\title{
Biodiversity of strongylids (Nematoda: Strongylidae) communities in domestic horses from Poland and Ukraine
}

\author{
T. KUZMINA ${ }^{1}$, S. KORNAŚ2 ${ }^{2}$, M. BASIAGA ${ }^{2}$, V. KHARCHENKO ${ }^{1}$, A. VYNIARSKA ${ }^{3}$
}

\begin{abstract}
${ }^{1}$ I.I. Schmalhausen Institute of Zoology, National Academy of Sciences of Ukraine, 15, B. Khmelnytskogo str., Kyiv, Ukraine, E-mail: taniak@izan.kiev.ua; ${ }^{2}$ Department of Zoology and Ecology, University of Agriculture in Krakow, al. Mickiewicza 24/28, Krakow, Poland; ${ }^{3}$ S.Z. Gzhytsky National Vniversity o Veterinary Medicine and Biotehnologies, 50, Pekarska str., Lviv, Ukraine
\end{abstract}

\begin{abstract}
Summary
Examination of the biodiversity of horse strongylid communities was performed on 51 domestic horses from Southern Poland and Western Ukraine by in vivo method. All horses were dewormed with macrocyclic lactone anthelmintics. Strongylids (34,715 specimens) were collected and identified by morphological criteria. In Poland, 25 strongylid species were found. Five cyathostome species dominated in the community. Large strongyles were found in $23.1 \%$ of horses and composed $0.56 \%$ of total strongylid number. General structure of strongylid community was multimodal with dominant, subdominant, background and rare species. In Ukraine, 19 species were found. Five cyathostome species dominated in the community. Strongylinae were found in $17.4 \%$ of horses and composed $0.07 \%$ of community. General structures of strongylid community were multimodal or bimodal depends on type of horse keeping conditions. Regularity of anthelmintic treatment was found to be more influential on strongylid community structure than differences in horse-keeping conditions at the both countries.
\end{abstract}

Keywords: Strongylidae; biodiversity; strongylid community; domestic horses; Ukraine; Poland

\section{Introduction}

Horses possess a rich intestinal parasites fauna (Lichtenfels, 1975; Matthew et al., 2004; Ogbourne, 1976; Ivashkin \& Dvojnos, 1984; Dvojnos \& Kharchenko, 1994). Nematodes from the family Strongylidae are the most prevalent and pathogenic group of intestinal parasites of equids worldwide (Dvojnos \& Kharchenko, 1994; Love et al., 1999; Lichtenfels et al., 2008).

Nowadays, 64 strongylid species were described in wild and domestic horses (Lichtenfels et al., 2008), which divided into two subfamilies - Strongylinae (strongylines or large strongyles) and Cyathostominae (cyathostomes or small strongyles). Strongyles are found to be the most prevalent group of horse parasites found in Poland and Ukraine (Dvojnos \& Kharchenko, 1994; Gawor, 1995; Kornaś et al., 2007, 2009, 2010; Kuzmina et al., 2005).

Several studies of species composition of strongylid communities of slaughtered domestic horses based on necropsy data were performed in Poland and Ukraine (Składnik, 1935; Sobieszewski, 1967; Ivashkin \& Dvojnos, 1984; Dvojnos \& Kharchenko, 1994; Gawor, 1995, Gundłach et al., 2004; Gawor et al., 2006; Kornaś et al., 2009). However, extensive post mortem examination of strongylid community was impossible for valuable brood horses from horse stud farms and riding clubs or for equids from natural reserves. In vivo examination of intestinal helminths after deworming of horses is the only method available to study strongylid community of these horses (OstermanLind et al., 2003; Kuzmina et al., 2005, 2007; Kornaś et al., 2007). This method allows performing simultaneous examination of intestinal parasites in large groups of horses and comparing parasite community in horses from various regions.

The aim of the current study was to examine the biodiversity of the strongylid communities in domestic horses from South-Eastern Poland and Western Ukraine. Special attention was given to evaluation the influence of various horse-keeping conditions of strongylid community structure in domestic horses.

\section{Material and methods}

The research was conducted in year 2007 on 28 horses of different breed (Hucul horses and Pure Blood Arabian horses) from a riding club and a horse stud farm from a southern Poland, and in 2010 on 23 domestic horses (Hucul and saddlers) from two horse-breeding farms in Zakarpatska and Ternopilska regions of Ukraine. Horses were kept under stable-paddock and stable-pasture keeping con- 
ditions. In Poland, all horses examined were dewormed irregularly (not often than twice a year); 6 of them were under stable-pasture keeping conditions, 22 - under stablepaddock conditions. In Ukraine, 11 horses were kept under stable-pasture conditions with low frequency treatments (about $1-2$ times per year) and 12 horses were under stable-paddock conditions with high frequency of regular treatments ( $4-5$ times per year). All horses have natural level of strongylid infection and have not been treated with any anthelmintics during at least 4 month before studies.

McMaster technique with sensitivity of 25 eggs per gram of faeces (Herd, 1992) was used to determine the level of horse infection by strongyles (in EPG - strongylid eggs per gram of faeces). We separated three levels of horse infections by strongylids: low level of infection (up to 200 EPG), moderate level (from 200 to 500 EPG) and high (more than 500 EPG). Coprological examination of every horse was performed twice - on a day before deworming and on the $14^{\text {th }}$ day after deworming (Coles et al., 2006).

All horses were dewormed with macrocyclic lactone anthelmintics: in Poland with "Growermina" (1 \% of ivermectine, Biowet Drawlew, Poland), in Ukraine - with "Univerm" (0.2\% aversectin C, FarmBioMed, Russia). Nematodes were collected after their expulsion from intestine with different methods. In Poland, faecal samples about $50 \%$ of one-time defecation $(2 \mathrm{~kg})$, were collected from the floor horse boxes of the infected horses, 24, 48 species in relation to the total number of strongylids found. Prevalence and proportion of every species in the community was calculated for all horses from each country (Ukraine and Poland).

The shape of the prevalence frequency distribution was determined according to description of Bucknell et al. (1996). Strongylid communities of horses kept under stable-paddock or stable-pasture keeping conditions were examined separately.

Biodiversity of the strongylid communities was examined using the Chekanovsky-Sørensen Index $\left(\mathrm{I}_{\mathrm{C}-\mathrm{S}}\right)$ (Pesenko, 1982). Bray-Curtis cluster analysis was performed on presence/absence data using the Biodiversity Professional 2.0 program.

\section{Results}

All horses examined were found to be infected with strongylids on the day before treatment. The levels of infection were mainly moderate (from 200 to 500 EPG) - in 6 horses $(46.2 \%)$ from Poland and in 18 horses $(78.3 \%)$ from Ukraine, or high $(500$ - 1500 EPG) - in 6 horses $(16.7 \%)$ in the both countries; only two horses $(15.4 \%)$ from Poland and four horses (17.4\%) from Ukraine had low level of infection (less than 200 EPG). No strongylid eggs were observed in faecal samples collected from all horses on the $14^{\text {th }}$ day after treatment.
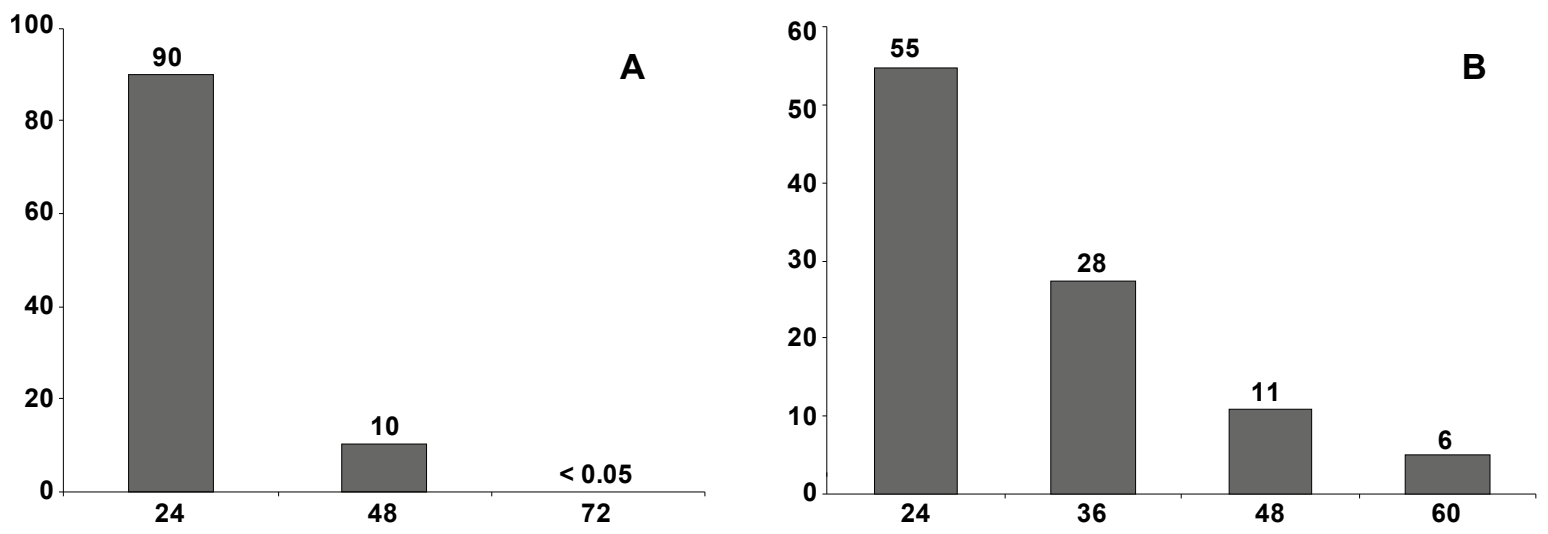

Fig. 1. The proportion (\%) of strongylids expelled in horse faeces after treatment with "Grovermina" in Poland (A) and "Univerm" in Ukraine (B): on horizontal axes - time after treatment, on vertical axes - proportion of strongylid expelled (\%)

and 72 hours after deworming. In Ukraine, faecal samples (200 g each) were collected from every horse 24, 36, 48 and 60 hours after treatment (Kuzmina et al., 2005). All nematodes expelled were collected manually after washing faeces with tape water or saline. Worms were fixed in $70 \%$ ethanol with addition of glycerine. Before identification nematodes were clarified with phenol-glycerine solution ( $80 \%$ of phenol, $20 \%$ of glycerine). Nematodes were identified under light microscope by morphological criteria using the key of Lichtenfels et al. (2008).

Data summaries and descriptive analyses were calculated using the Microsoft ${ }^{\mathrm{TM}}$ Excel. The proportion of every individual species in the strongylid community was calculated as the number of the specimens of the particular
Totally, 21,562 strongylid specimens were collected from 28 horses in Poland and 13,153 specimens were collected from 23 horses in Ukraine. From 97 to 4,730 strongylid specimens were collected and identified per horse. No significant correlation between EPG and number of worms expelled from horse intestine were found.

The majority of worms were expelled in faeces of all horses in 24 hours after deworming with the both drugs (Fig. 1).

Totally, 25 strongylid species from 10 genera were found in horses from Poland - 6 species of subfamily Strongylinae and 19 species - of Cyathostominae (Fig. 2). From 4 to 21 species (average 11.2 \pm 4.8 S.D.) parasitized per one horse.

Five cyathostome species (C. catinatum, C. nassatus, 
C. longibursatus, $C$. goldi and $C$. pateratum) dominated in the strongylid community. They were found in more than $80 \%$ of horses and together composed $72 \%$ of total strongylid number. Large strongyles (Strongylinae) were found in $23.1 \%$ of horses examined; their prevalence varied from $4 \%$ to $18 \%$ (Fig. 2). Proportion of large strongyles in the community was minor - only $0.57 \%$. From 1 to 5 Strongylinae species (average $2.7 \pm 2.1$ S.D.) were found per one horse in Poland.

The shape of the prevalence frequency distribution of strongylid species in domestic horses from Poland was multimodal at the both horse farms with stable-paddock and stable-pasture horse keeping conditions (Fig. 3). Four groups of species including dominant (prevalence $>80 \%$ ), subdominant (prevalence - $60-80 \%$ ), background (prevalence - 30 - 60\%) and rare (prevalence $<30 \%$ ) species can be separated in the strongylid community.

In Western Ukraine, 19 strongylid species from 8 genera were found in domestic horses - two species of Strongylinae and 17 - of Cyathostominae (Fig. 4). From 6 to 16 species (average $10.1 \pm 3.24$ S.D.) parasitized per one horse.

\section{Prevalence (\%)}

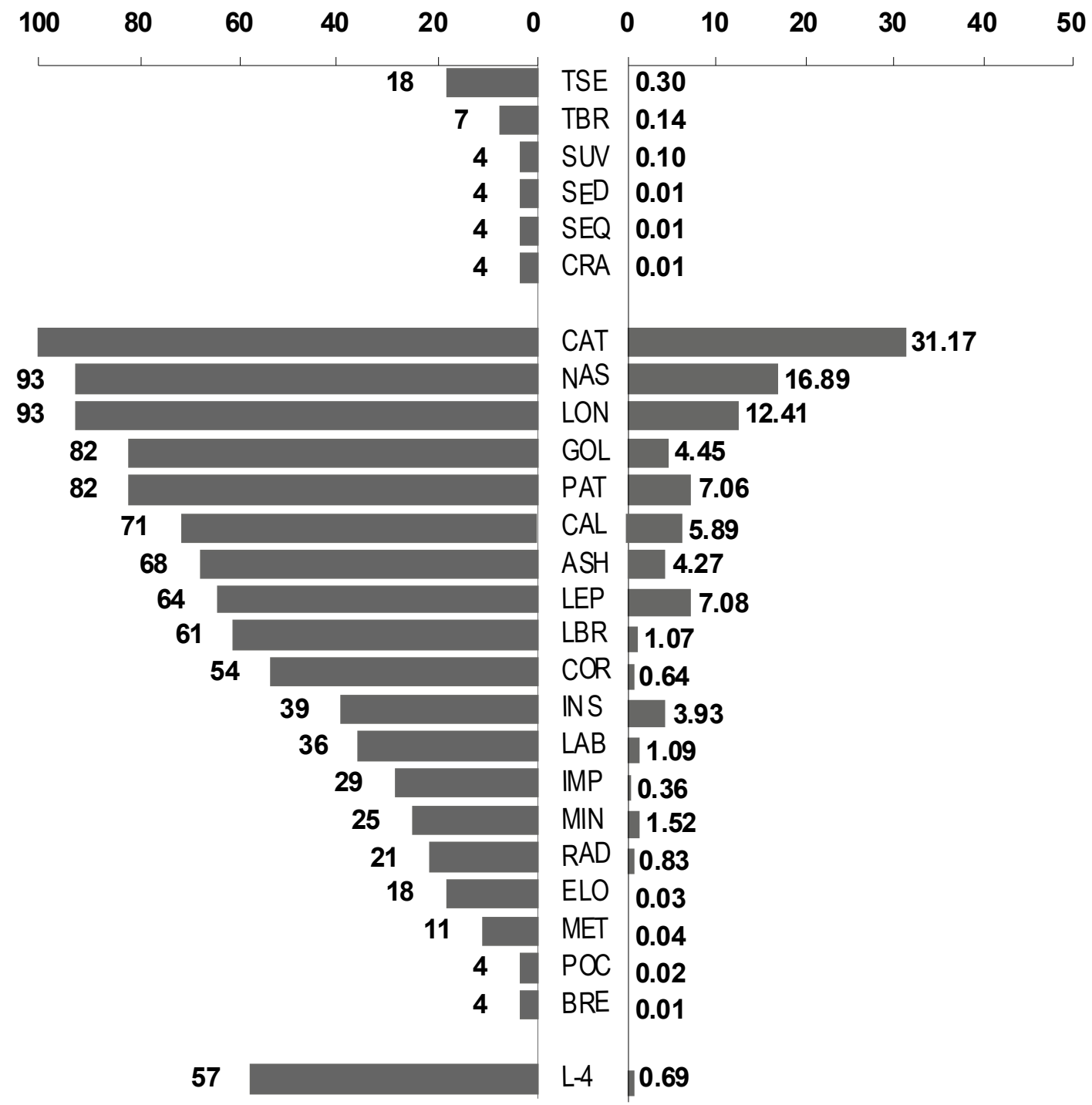

Fig. 2. Prevalence and proportion of individual species in the strongylid community of horses from South-Eastern Poland: ASH - Cylicocyclus ashworthi, ACU - Craterostomum acuticaudatum, BRE - Cylicocyclus brevicapsulatus, CAL - Cylicostephanus calicatus, CAT - Cyathostomum catinatum, COR - Coronocyclus coronatus, ELO - Cylicocyclus elongatus, GOL - Cylicostephanus goldi, IMP - Poteriostomum imparidentatum, INS - Cylicocyclus insigne, LAB - Coronocyclus labiatus, LBR - Coronocyclus labratus, LEP - Cylicocyclus leptostomum,

LON - Cylicostephanus longibursatus, MET - Parapoteriostomum mettami, MIN - Cylicostephanus minutus, NAS - Cylicocyclus nassatus,

PAT - Cyathostomum pateratum, POC - Petrovinema poculatum, RAD - Cylicocyclus radiatus, TSE - Triodontophorus serratus, TBR - Triodontophorus brevicauda, SED - Strongylus edentatus, SEQ - Strongylus equinus, SVU - Strongylus vulgaris, L-4 - parasitic larvae of the $4^{\text {th }}$ stage. 

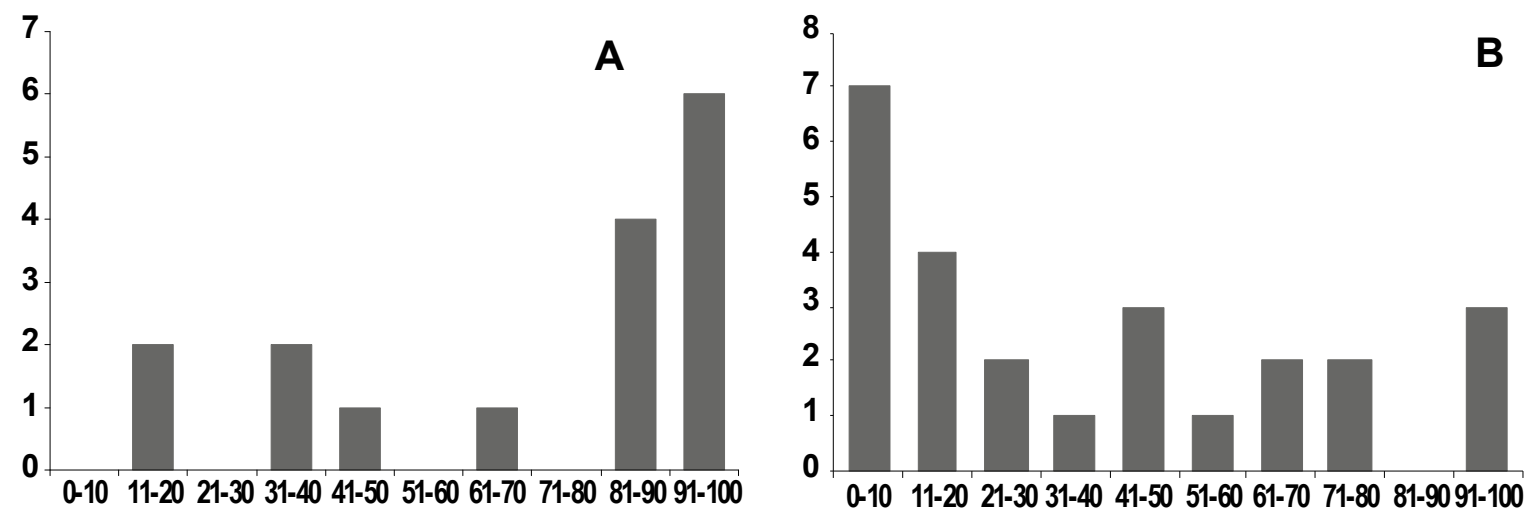

Fig. 3. Distribution of the strongylid species from the domestic horses from Poland into prevalence classes: A - at the stud farm with stablepasture horse keeping conditions, $\mathrm{B}$ - with stable-paddock horse keeping conditions.

On horizontal axes - prevalence classes, on vertical axes - number of species.

Five cyathostome species (C. nassatus, C. longibursatus, $C$. catinatum, $C$. calicatus and $C$. coronatus) were the most prevalent in strongylid community. They were found in more than $80 \%$ of horses and together they composed more than $83.2 \%$ of total strongylid number. Large strongyles (Strongylinae) were found in $17.4 \%$ of horses examined; however their proportion in strongylid community was minor - only $0.06 \%$. From 1 to 2 Strongylinae species (average $1.3 \pm 0.5$ S.D.) were found per one horse in Ukraine.

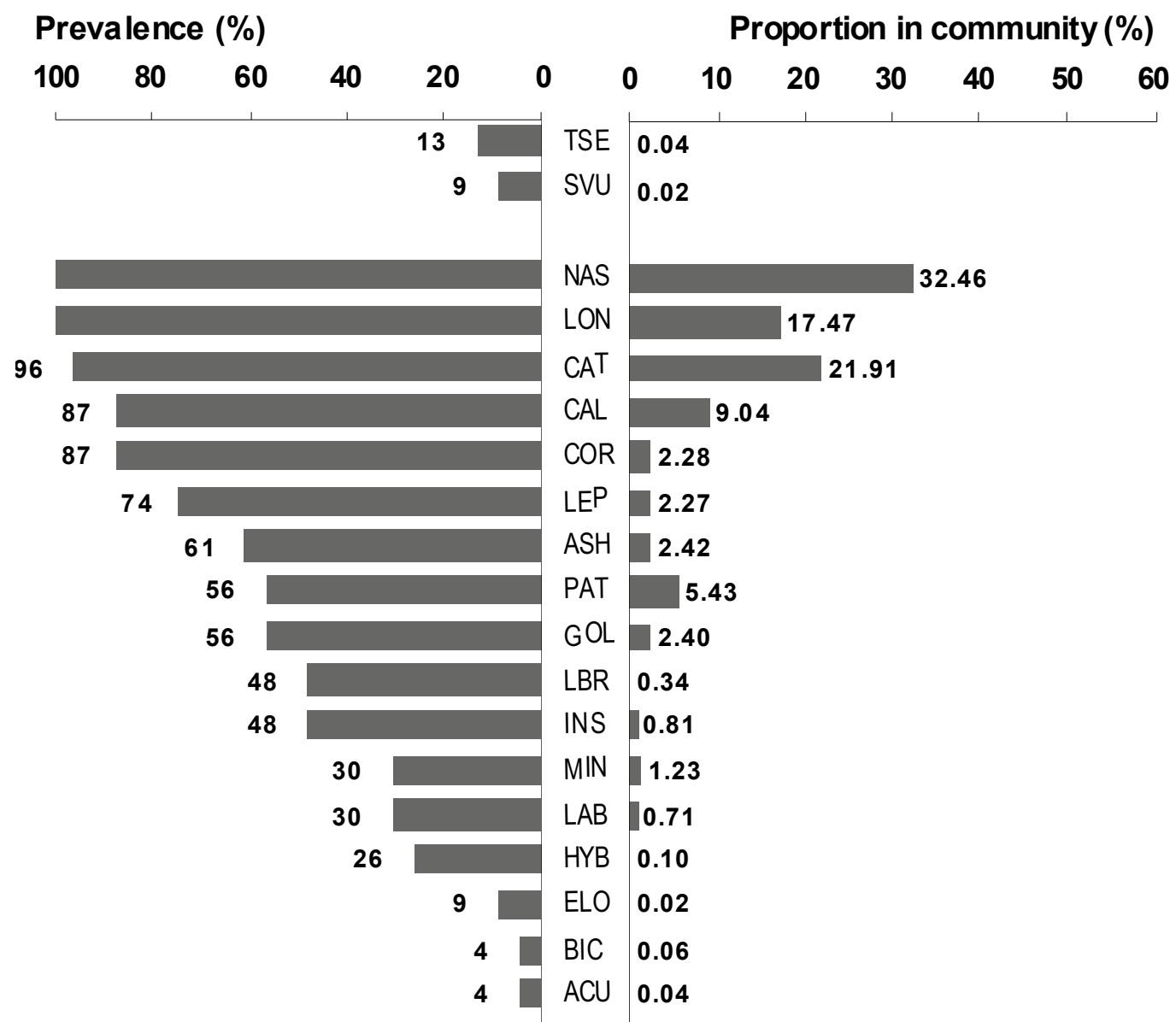

Fig. 4. Prevalence and proportion of individual species in the strongylid community of horses from Western Ukraine: ASH - Cylicocyclus ashworthi, ACU - Craterostomum acuticaudatum, BIC - Cylicodontophorus bicoronatus, CAL - Cylicostephanus calicatus, CAT - Cyathostomum catinatum, COR - Coronocyclus coronatus, ELO - Cylicocyclus elongatus, GOL - Cylicostephanus goldi, HYB Cylicostephanus hybridus, INS - Cylicocyclus insigne, LAB - Coronocyclus labiatus, LBR - Coronocyclus labratus, LEP - Cylicocyclus leptostomum, LON - Cylicostephanus longibursatus, MIN - Cylicostephanus minutus, NAS - Cylicocyclus nassatus, PAT - Cyathostomum pateratum, TSE - Triodontophorus serratus, SVU - Strongylus vulgaris, L-4 - parasitic larvae of the $4^{\text {th }}$ stage 
The shape of the prevalence frequency distribution of strongylid species in domestic horses from Western Ukraine was multimodal or bimodal depends on type of horse keeping condition (Fig. 5). Primitive Hutsul horses that were kept under stable-pasture conditions with irregular anthelmintic treatment (less than 2 times per year) possessed multimodal structure of community. At the same time domestic horses that were under stable-paddock keeping conditions with regular frequent treatment (about $4-5$ times per year) possessed bimodal structure of strongylid community with dominated and rare species (similar to the "core - satellite" mode by Hansky, 1982).

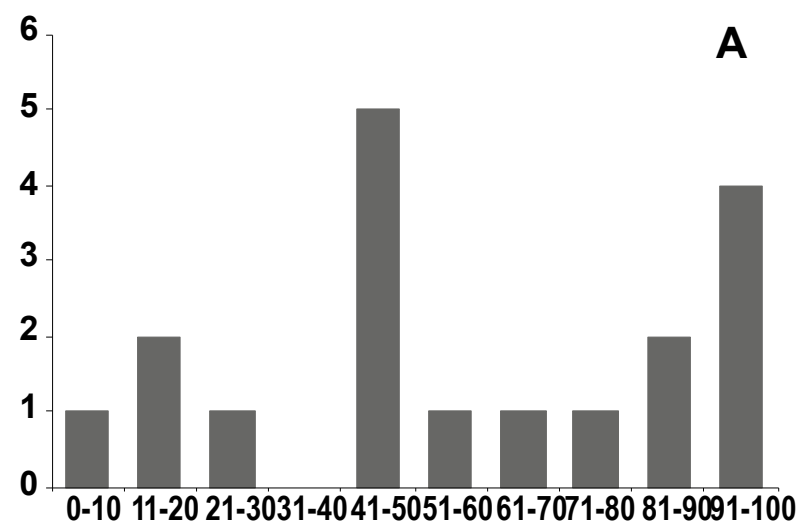

2005, 2007; Kornaś et al., 2007). Thus, we believe our results are comparable with data of other authors who studied horse strongylid communities in Ukraine and Poland (Składnik, 1935; Sobieszewski, 1967; Gawor, 1995; Gundłach et al., 2004; Kornaś et al., 2009) as well as in other countries (Ogbourne, 1976; Eydal, 1983; Reinemeyer et al., 1984; Bucknell et al., 1995, 1996; Várady et al., 2000; Anjos \& Rodrigues, 2003; CollobertLaugier et al., 2002).

We used two modifications of the in vivo technique of nematodes collection at the current studies: in Ukraine it was the in vivo methods described before (Kuzmina et al.,

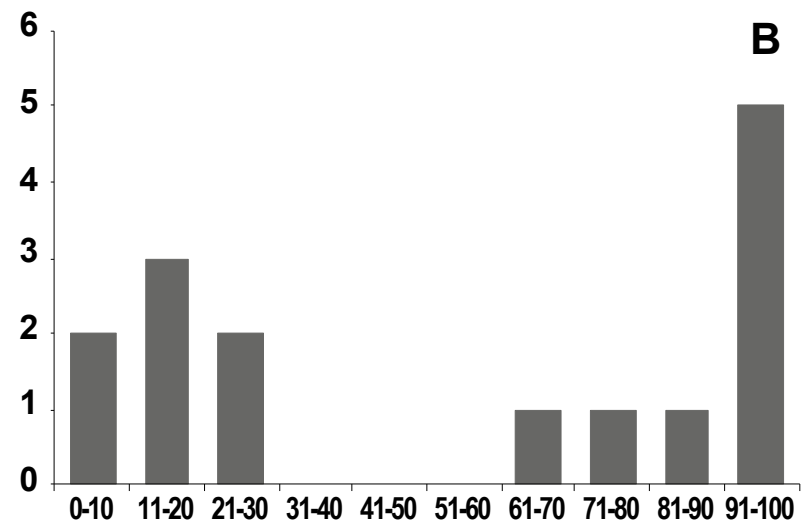

Fig. 5. Distribution of the strongylid species from the Western Ukraine horses into prevalence classes: A - multimodal structure at the stud farm with stable-pasture horse keeping conditions; B - bimodal structure in with farm stable-paddock keeping conditions. On horizontal axes - prevalence classes, on vertical axes - number of species.

Biodiversity of the strongylid communities of domestic horses from Southern Poland and Western Ukraine are rather similar; the Chekanovsky-Sørensen Index $\left(\mathrm{I}_{\mathrm{C}-\mathrm{S}}\right)$ is 0.77 .

Species richness of the strongylid communities in horses kept under stable-pasture conditions in the both countries is more similar $\left(\mathrm{I}_{\mathrm{C}-\mathrm{S}}=0.82\right)$ than in horses kept under stable-paddock conditions $\left(\mathrm{I}_{\mathrm{C}-\mathrm{S}}=0.70\right)$.

Bray-Curtis cluster analysis did not reveal significant differences in strongylid communities of horses kept under stable-paddock keeping conditions in comparison with stable-pasture keeping conditions.

Regularity of deworming has more influence on strongylid community than difference in horse-keeping conditions. Thus, species richness of the strongylid community is much higher in farms with irregular deworming (26 species compare with 15 in the current study). Moreover, we found 6 Strongylinae species in irregularly dewormed horses in comparison with 1 species (C. acuticaudatum) in horses treated $4-5$ times per year. Similarity of the strongylid fauna was also rather low $\left(\mathrm{I}_{\mathrm{C}-\mathrm{S}}=0.65\right)$.

\section{Discussion}

The results presented herein are the first comparative investigation of horse strongylid communities in Ukraine and Poland based on in vivo studies. The effectiveness of intravital collection of intestinal helminths was shown to provide data comparable with those based on post mortem methods (Osterman Lind et al., 2003; Kuzmina et al.,
2005); in Poland the method was slightly modified (the 36 hours sample was excluded). That was the reason of difference in proportion of the strongylids expulsed in the both countries (Fig. 1). However, the total proportion of strongylid collected in Ukraine during 24 and 36 hours was $83 \%$ what is comparable with data from Poland. Moreover, we compared proportions of every species in the strongylid community that allowed us to avoid any possible discrepancies in total strongylid numbers collected from every horse in the both countries.

In present study, 23 species of strongylids (18 of Cyathostominae and 5 of Strongylinae) were identified in domestic horses in Poland. All these species have been reported as horse parasites in Poland previously (Składnik, 1935; Sobieszewski, 1967; Gawor, 1995). Comparison of our data with information from previous studies demonstrated changes in strongylid community structure occurred during last decades. Gawor (1995) reported 7 species of large strongylids with prevalence from $2 \%$ (Triodontophorus nipponicus) up to $74 \%$ (Strongylus vulgaris). In earlier studies of Sobieszewski (1967) 7 species of Strongylinae were also found, with prevalence from $12 \%$ (Triodontophorus nipponicus) up to $78 \%$ (S. vulgaris). In our studies conducted in South-Eastern Poland, 5 species of Strongylinae were found with prevalence not larger than $17.9 \%$. The common species, $S$. vulgaris, was found only in $4 \%$ of horses examined.

The similar situation was observed also in horses from Western Ukraine. We found 19 species of Strongylidae (17 
of Cyathostominae and 2 of Strongylinae). General prevalence of Strongylinae was as large as $13.1 \%$, and their proportion in strongylid community was just $0.06 \%$. Thus, this proportion was sufficiently lower if compared with that reported in previous studies (Ivashkin \& Dvojnos, 1984; Dvojnos \& Kharchenko, 1994); where Triodontophorus and Strongylus occurred in $90 \%$ and $100 \%$ of horses examined, respectively.

In our opinion, the decrease of large strongylids' proportion in communities is related to frequent use of highly effective anthelminthics, first of all, macrocyclic lactones (ivermectin, moxydectin) that efficiently eliminate strongylins with longer life cycles from the strongylid community. Similar situation was observed in many countries where cyathostomes become the most prevalent and important group of equine parasites at this time (Herd, 1990; Love et al., 1999; Lyons et al., 1999, 2000; Collobert-Laugier et al., 2002; Kaplan, 2002; Corning, 2009; Craven et al., 1998; Osterman Lind et al., 1999; Konigova et al., 2001).

The present study revealed the decrease of species diversity of horse strongylids compared to that reported in previous studies (Składnik 1935; Sobieszewski, 1967; Gawor, 1995; Dvojnos \& Kharchenko, 1994). Such species as Cylicostephanus asymetricus, C. hybridus, C. ultrajectinus, Cylicodontophorus bicoronatus, Poteriostomum ratzii, Parapoteriostomum euproctus and Gyalocephalus capitatus reported by Składnik (1935) in horsed from Poland were not observed in the present study. The prevalence and, especially, intensity of horse infection by these species was very low. That is why these rare species could be easily missed out if a small number of nematodes had been identified per one horse (Chapman et al., 2003). In Ukraine, 34 strongylid species were registered in horses in late $70^{\text {th }}$ of XX century (Ivashkin \& Dvojnos, 1984; Dvojnos \&, Kharchenko, 1994). In our opinion decreasing of biodiversity of strongylid communities in the both countries can be explained by two reasons. In the current study we examined only 51 horses, whereas previous researchers examined much more horses and had more chances to find more of rare strongylid species. From the other hand, regular application of modern anthelmintic drugs, especially high effective macrocyclic lactones, eliminate rare strongylid species from the parasite community.

According to the results of the present study, 5- 7 most prevalent species of Cyathostominae were the core of horse strongylid communities both in Poland and in Ukraine. Those species were observed in more than $80 \%$ of horses examined and composed totally $72 \%$ and $83.2 \%$ of strongylids' quantity, correspondingly. The lowest biodiversity of strongylids was observed in horses from the farm where the anthelmintic treatments were frequent; 6 predominat species composed $92.1 \%$ of communities there.

The similar situation is observed in a number of countries, especially those where the anthelmintic resistance occurs in cyathostomes (Drudge et al., 1983; Burger \& Bauer, 1987; Tolliver et al., 1993; Lyons et al., 1996; Kaplan,
2002; Osterman Lind et al., 2003, 2007; Konigova et al., 2001). We presume that the dominant cyathostome species have genetic diversity necessary to survive the strong selection pressure of anthelmintic treatments and develop the anthelmintic resistance (Kuzmina \& Kharchenko, 2008).

The present study revealed differences in species composition of strongylid communities of horses kept under different management systems (stable-pasture and stable-paddock keeping conditions) in the both countries. Horses kept under stable-pasture keeping conditions with irregular anthelmintic treatment in Poland and Ukraine were observed to have similar communities of strongylids. The frequency of regular anthelmintic treatments was approved to influence on general structure of strongylid communities, which becomes bimodal. Rare species with low intensity disappear, and the prevalence of background species (prevalence $30-60 \%$ ) decreases. Such bimodal structure of strongylid communities was often observed in domestic equids exposed to regular anthelmintic treatments (Bucknell et al., 1996; Kuzmina et al., 2005; Kuzmina, Kuzmin, 2008).

The present study thus demonstrates that decrease of species diversity and changes in natural structure of strongylid communities in domestic horses from Poland and Ukraine depends rather on the frequency of anthelmintic treatments with use of highly effective anthelmintics than on differences in horse keeping conditions in both countries.

\section{Acknowledgements}

The authors thank to Dr. Iurii Kuzmin from the Institute of Zoology NAS of Ukraine for his assistance in revising the manuscript.

\section{References}

Anjos, D. H., Rodrigues, M. L. (2003): Structure of the community of the Strongylidae nematodes in the dorsal colon of Equus caballus from Rio de Janeiro state-Brazil. Vet. Parasitol., 112: 109 - 116. DOI: 10.1016/S03044017(02)00424-7

Bucknell, D. G., GAsser, R. B., Beveridge, I. (1995): The prevalence and epidemiology of gastrointestinal parasites of horses in Victoria, Australia. Int. J. Parasitol., 25: 711 - 724. DOI: 10.1016/0020-7519(94)00214-9

Bucknell, D., Hoste, H., Gasser, R. B., Beveridge, I. (1996): The structure of the community of strongyloid nematodes of domestic equids. J. Helminthol., 70: $185-$ 192. DOI: 10.1017/S0022149X0001539X

Burger, H. J., BAUER, C. (1987): Efficacy of four anthelmintics against benzimidazole-resistant cyathostomes of horses. Vet. Rec., 120: $293-296$.

Chapman, M. R., Kearney, M. T., Klei, T. R. (2003): Equine cyathostome populations: accuracy of species composition estimations. Vet. Parasitol., 116(1): $15-21$. DOI: $10.1016 / \mathrm{S} 0304-4017(03) 00239-5$ 
Coles, G. C., Jackson, F., Pomroy, W. E., Prichard, R. K., Von SAmson-Himmelstjerna, G., Silvestre, A., TAYLOR, M. A., VERCRUYSSE, J. (2006): The detection of anthelmintic resistance in nematodes of veterinary importance. Vet. Parasitol., 136: 167 - 185. DOI: 10.1016/j.vetpar.2005.11.019

Collobert-Laugier, C., Hoste, H., Sevin, C., DORCHIES, P. (2002): Prevalence, abundance and site distribution of equine small strongyles in Normandy, France. Vet. Parasitol., 110: 77 - 83. DOI: 10.1016/S03044017(02)00328-X

CoRnING, S. (2009): Equine Cyathostomins: A review of biology, clinical significance and therapy. Parasit. Vectors, Supplement 2: 1 - 6. DOI: 10.1186/1756-3305-2-S2-S1

Craven, J., Bjorn, H., Henriksen, S. A., Nansen, P., LARSEN, M., LENDAL, S. (1998): Survey of anthelmintic resistance on Danish horse farms, using five different methods of calculating faecal egg count reduction. Equine Vet. J., 30: 289 - 293. DOI: 10.1111/j.2042-3306.1998.tb0 4099.x

Drudge, J. H., Lyons, E. T., SwerczeK, T. W., Tolliver, S. C. (1983): Cambendazole for strongyle control in a pony band: selection of a drug-resistant population of small strongyles and teratologic implications. Am. J. Vet. Res., 44: $110-114$.

Dvojnos, G. M., Kharchenko, V. A. (1994): Strongylida of wild and domestic horses. Naukova Dumka, Kiev. 234 pp. [In Russian].

EYDAL, M. (1983): Gastrointestinal parasites in horses in Iceland. J. Agric. Res. Iceland, 15: 3 - 28.

GAWOR, J. J. (1995): The prevalence and abundance of internal parasites in working horses autopsied in Poland. Vet. Parasitol., 58: 99 - 108. DOI: 10.1016/0304-4017(94) 00698-C

Gawor, J., Kornaś, S., Charcenko, V., Nowosad, B., SKALSKA, M. (2006): Intestinal parasites and health problems in horses in different breeding systems. Med. Wet., 62, 331 - 334 [In Polish].

Gundłach, J. L., SAdzikowski, A. B., TomczuK, K., STUDZIŃSKA, M. (2004): Parasites of alimentary tract of horses from Lublin district in the light of coproscopic and gross anatomopatological examinations. Med. Wet., 60: 1089 - 1092 [In Polish]

HANSKI, I. (1982): Dynamics of regional distribution: the core and satellite species hypothesis. Oikos, 38: $210-221$.

HERD, R. P. (1990): The changing world of worms-the rise of the cyathostomes and the decline of Strongylus vulgaris. Compend. Contin. Educ. Vet., 12: 732 - 736.

HERD, R. P. (1992): Performing equine fecal egg counts. Vet. Med., 87: 240 - 244.

IVASHKIN, V. M., DvoJNOS, G. M. (1984): Identification key of helminth of horses. Kiev: Naukova Dumka, 162 pp. [In Russian].

KAPLAN, R. M. (2002): Anthelmintic resistance in nematodes of horses. Vet. Res., 33: 491 - 507. DOI: 10.1051/vetres:2002035

Konigova, A., Varady, M., CorbA, J. (2001): The prevalence of equine gastrointestinal parasites in the
Slovak Republic. Helminthologia, 38: 211 - 214.

KornaŚ S., SKALSKA M., NowOSAD B., GAWOR J. (2007): The communities of cyathostomes (Cyathostominae) in one-year-old and two-year-old Pure Blood Arabian mares. Wiad. Parazytol., 53: 325 - 329 [In Polish].

Kornaś, S., Skalska, M., Nowosad, B., Gawor, J., KHARCHENKO, V., CABARET, J. (2009): Occurrence of strongyles (Strongylidae) in horses from small farms on the basis of necropsy. Pol. J. Vet. Sci., 12: 225 - 230.

Kornaś S., CABARET J., SKalSKa M., NowOSAD B. (2010): Horse infection with intestinal helminths in relation to age, sex, access to grass and farm system. Vet. Parasitol., 174: 285 - 291. DOI: 10.1016/j.vetpar.2010.09.007

Kuzmina, T. A., Kharchenko, V. A., Starovir, A. I., Dvojnos, G. M. (2005): Analysis of the strongylid nematodes (Nematoda: Strongylidae) community after deworming of brood horses in Ukraine. Vet. Parasitol., 131: 283 - 290. DOI: 10.1016/j.vetpar.2005.05.010

KuZmina, T. A., KharchenKo, V. A., Zvegintsova, N. S. (2007): Comparative study of the intestinal strongylid communities of equidae in the Askania-Nova biosphere reserve. Ukraine. Helminthologia, 44: 62 - 69. DOI: 10.2478/s11687-007-0005-9

Kuzmina, T. A., Kharchenko, V. O. (2008): Anthelmintic resistance in cyathostomins of brood horses in Ukraine and influence of anthelmintic treatments on strongylid community structure. Vet. Parasitol., 154: 277 - 288. DOI: 10.1016/j.vetpar.2008.03.024

KuzminA, T. A., KuzMin, Y. I. (2008): The strongylid community of working donkeys (Equus asinus L.) in Ukraine. Vestnik Zoologii, 42(2): 99 - 104.

LICHTENFELS, J. R. (1975): Helminths of domestic equids. Illustrated keys to genera and species with emphasis on North American forms. Proc. Helminthol. Soc. Wash., 42: $1-92$

Lichtenfels J. R., Kharchenko V. A., Dvojnos G. M. (2008): Illustrated identification keys to strongylid parasites (Strongylidae: Nematoda) of horses, zebras and asses (Equidae). Vet. Parasitol., 156: 4 - 161. DOI: 10.1016/ j.vetpar.2008.04.026

Love, S., MurPhy, D., Mellor, D. (1999): Pathogenicity of cyathostome infection. Vet. Parasitol., 85: 113 - 122. DOI: 10.1016/S0304-4017(99)00092-8

Lyons, E., Tolliver, S., Drudge, J., Stamper, S., SWERCZEK, T., Granstrom, D. (1996): A study (19771992) of population dynamics of endoparasites featuring benzimidazole-resistant small strongyles (population $\mathrm{S}$ ) in Shetland ponies. Vet. Parasitol., 66: 75 - 86. DOI: 10.1016/S0304-4017(96)00998-3

Lyons, E. T., Tolliver, J. H., Drudge, D. E. (1999): Historical perspective of cyathostomes: prevalence, treatment and control programs. Vet. Parasitol., 85: 97 112. DOI: 10.1016/S0304-4017(99)00091-6

Lyons, E. T., SwerczeK, T. W., Tolliver, S. C., BAir, H. D., Drudge, J. H., ENNIS, L. E. (2000): Prevalence of selected species of internal parasites in equids at necropsy in central Kentucky (1995 - 1999). Vet. Parasitol., 92: 51 - 62. DOI: 10.1016/S0304-4017(00)00266-1 
Matthew, J. B., Hodgkinson, J. E., Dowdall, S. M. J., Proudman, C. J. (2004): Recent developments in research into the Cyathostominae and Anoplocephala perfoliata. Vet. Res., 35: 371 - 381. DOI: 10.1051/vetres:2004026 OgBourne, C. P. (1976): The prevalence, relative abundance and site distribution of nematodes of the subfamily Cyathostominae in horses killed in Britain. $J$. Helminthol., 50: $203-214$.

Osterman Lind, E., HÖGLUnd, J., LJungström, B.L., Nilsson, O., UGgla, A. (1999). A field survey on the distribution of strongyle infections of horses in Sweden and factors affecting faecal egg counts. Equine Vet. J., 31: 68 - 72. DOI: 10.1111/j.2042-3306.1999.tb03793.x

Osterman Lind, E., Eysker, M., Nilsson, O., UGgla, A., HöGlund, J. (2003): Expulsion of small strongyle nematodes (Cyathostomin spp.) following deworming of horses on a stud farm in Sweden. Vet. Parasitol., 115: 289 - 299. DOI: 10.1016/S0304-4017(03)00200-0

Osterman Lind, E., KuzMina, T., Uggla, A., Waller, P. J., HöGLUND, J. (2007): A field study on the effect of some anthelmintics on cyathostomins of horses in Sweden. Vet. Res. Commun., 31: 53 - 65. DOI: 10.1007/s11259006-3402-5

RECEIVED FEBRUARY 3, 2011
Pesenko, Y. A. (1982): Principles and methods of quantitative analysis in faunistic investigations. Moscow: Nauka, 284 pp. [In Russian].

Reinemeyer, C. R., Smith S. A., Gabel A. A., Herd R. P. (1984): The prevalence and intensity of internal parasites of horses in the U.S.A. Vet. Parasitol., 15: 75 - 83. DOI: 10.1016/0304-4017(84)90112-2

SkŁADNIK, J. (1935): Trichoneminae u koni w Polsce. Wiad. Wet., 14: 137 - 183 [In Polish].

SoBIESZEWSKI, K. (1967): Parasitic nematodes of alimentary tracts of horses in the Lublin Palatinate. Acta Parasitol. Pol., 15: 103 -108 [In Polish].

Tolliver, S. C., Lyons, E. T., DrudGe, J. H., StAmper, S., Granstrom, D. E. (1993): Critical tests of thiabendazole, oxibendazole, and oxfendazole for drug resistance of population-B equine small strongyles (1989 and 1990). Am. J. Vet. Res., 54: 908 - 913.

VÁrAdy, M., KÖNIGOVÁ, A., ČORBA, J. (2000): Benzimidazole resistance in equine cyathostomes in Slovakia. Vet. Parasitol., 94 (1-2): 67 - 74. DOI: 10.1016/S0304-4017(00)00366-6

ACCEPTED MARCH 4, 2011 